\title{
Fair Value as a Measurement Basis: The Case of Agriculture in Portugal
}

\author{
Maria da Conceição da Costa Marques
}

\section{ABSTRACT}

\begin{abstract}
The entities that operate in the agricultural activity, during the management must make decisions, which depend a lot on the information that is available in the opportune moment. Timely information and reliable accounting records are essential in this process. For the measurement of biological assets at fair value, there must be an active market. The fair value is based on the current location and condition of the asset and will therefore result from its price in the relevant market. There may, however, be advantages and disadvantages in the use of fair value in the measurement of a biological asset, a topic that will develop in this article.
\end{abstract}

Keywords: Agriculture, biological assets, agricultural product, fair value, decision making, accounting, IPSAS 27, IAS 41.
Submitted : April 18, 2021

Published : June 02, 2021

ISSN: 2507-1076

DOI: $10.24018 /$ ejbmr.2021.6.3.855

Maria da Conceição da Costa Marques* Coordinating Professor, ISCAC Coimbra Business School, Department of Business Sciences, Portugal.

(e-mail: mmarques@iscac.pt)

(e-mail: mcmarques.pt ${ }^{@}$ gmail.com)

*Corresponding Author

\section{INTRODUCTION}

In the globalized world we live in, there are several regulations that define the structure for reporting performance, income, and capital structure of companies. However, in practice, what is verified is that in different demonstrations the performance is presented inconsistently and with various evaluation methods.

The agricultural sector can be described as the set of economic activities that generate agricultural products and other more valuable products, using land and seeds. Increasing industrialization and establishing social and economic well-being have increased the importance of this sector. Previously, agricultural production was considered essential to face hunger and poverty; today, as at that time, it is a raw material for industry, namely the food industry, packaging, storage, and marketing. Agriculture provides products for the pharmaceutical, energy and textile industries, as well as the food industry [1]

The entities that operate in the agricultural activity, during the management must make decisions, which depend a lot on the information available at the right time. Timely information and reliable accounting records are essential to ensure successful decision-making.

In Portugal, entities operating in the agricultural area may apply, depending on the sector in which they operate and their size, the international standards IAS 41 - Agriculture and IPSAS 27 with the same designation, the Accounting and Financial Reporting Standard (NCRF) 17 - Agriculture, as well as Public Accounting Standard (NCP) 11, with the same name.

According to the IASB, fair value is the amount by which an asset can be exchanged, or a liability settled between knowledgeable and willing parties in a transaction in which there is no relationship between them. A biological asset shall be measured at initial recognition and at each balance sheet date at its fair value less estimated costs at the point of sale. If it is not possible to reliably measure the fair value, the biological asset shall be measured at cost less any accumulated depreciation and any accumulated impairment loss. The agricultural product harvested from the biological assets of an entity shall be measured at its fair value less estimated costs at the point of sale at the time of harvest.

For the measurement of biological assets at fair value there must be an active market that is considered "as a market in which all the following conditions are verified: a) The items traded in the market are homogeneous; b) Can be found at any time buyers and sellers ready to buy and sell; and c) Prices are available to the public [17], [10], [11]. There may be advantages and disadvantages in the use of fair value in agriculture.

This article deals with the use of this measurement base in agriculture, more specifically within the public sector, as well as the related accounting aspects.

\section{Agricultural ACTIVITY}

Agricultural activity is the management by an entity of the biological transformation and harvesting of biological assets for sale, free or symbolic retribution, conversion into agricultural products or additional biological assets for sale or for free distribution or with symbolic retribution. Examples of agricultural activities are livestock farming, forestry, annual or seasonal crops, cereals, orchards and plantations, floriculture, and aquaculture (including nurseries) [19].

We can therefore distinguish some common features in agricultural activities, namely:

- The capacity for transformation that makes living animals and plants capable of biological transformation.

- Processing management to facilitate biological 
transformation by improving, or at least maintaining, the necessary conditions for the process to take place (e.g., providing nutritional levels, humidity, temperature, fertility, and light).

On the other hand, ocean fishing and deforestation are examples of non-agricultural activities, as they occur in unmanaged areas.

Agricultural activities are interpreted and distinguished because management promotes and manages the biological conversion (e.g., management can influence the development of live animals or vegetation, decrease in production as a result of production of new biological assets through a breeding program ) and is able to measure the quality and quantity with which these assets are modified (sheep, plants for harvest), or how wheat and vegetables are harvested, or fruit trees, vines and tea [2]. The same authors give as examples of agricultural activities the following:

- Breeding of livestock, fish, or poultry.

- Stud farms (e.g., raising horses or cattle.

- Forestry.

- Cultivation of vineyards, orchards, or plantations.

- Floriculture, fish farming.

To allow a better understanding of these themes, the following figure shows us the process of approximation and representation of agricultural activities. It can thus be seen that biological assets, agricultural products, processing, and harvesting can be separated (Fig. 1).

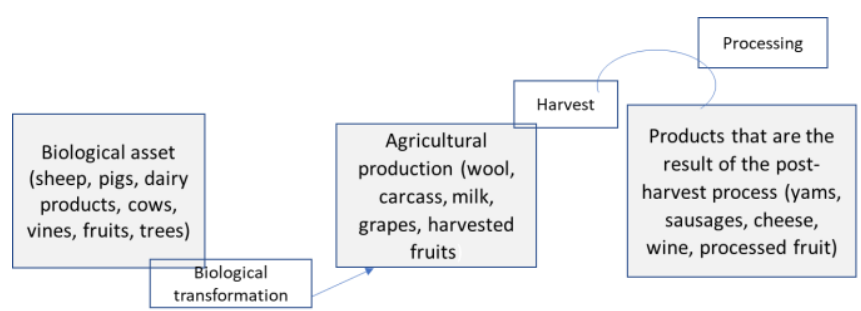

Fig. 1. Process of agricultural activities. Source: Adapted from [2].

\section{SCOPE}

The adoption of the Accounting Standardization System in Portugal on 1 January 2010 brought significant changes to accounting, especially for the agricultural sector. The introduction of IPSAS also brought a new approach to agriculture in public entities [3].

In the last decades we have witnessed a growing development of public accounting, in particular through the evolution of the international panorama and consequent needs for modernization, which led to the implementation of reforms in the Portuguese Public Administration (PA) at budget, equity and analytical level, to the needs of change.

In fact, from the 90's a process of reform of the AP was implemented, with the aim of bringing the system used by public entities closer to that used by private companies. This change allowed the introduction of new accounting systems in the different public entities.

With the publication of the basic law of public accounting (Law $n^{\circ} 8 / 90$, of February 20), the bases were established for the emergence of a new regime for the financial administration of the State, which would eventually allow the creation of the Plan Public Accounting Officer (POCP), approved in 1997. The introduction and approval of the POCP led the public accounting to have new paradigms, its main objective being to facilitate and assist decision making, by providing information of a character economic, financial and management. Until then, the main concerns of public entities and users of public financial information were essentially related to the rendering of accounts and the legal formalities to which they were obliged. Until then, the main concerns of public entities and users of public financial information were essentially related to the accountability and legal formalities to which they were obliged.

The Accounting Standardization System for Public Administrations (SNC-AP) was approved by Decree-Law no. $192 / 2015$ of 11 September and constitutes the new accounting system for public administrations. With this approval, accounting standardization for the public sector follows the same guidelines as accounting standardization for private sector entities or even the non-profit sector. There is, however, an important difference in relation to these, which is the delay in the adjustment process.

\section{Methodology}

"An investigation is, by definition, something that is sought. It is a path towards better knowledge and must be accepted as such, with all the hesitations, deviations, and uncertainties that this entails" [4].

Qualitative research implies an emphasis on processes and meanings, in-depth analysis, obtaining even the perceptions of the elements investigated [5]. In turn, quantitative research is concerned with objective measurement and quantification of results [6].

Bibliographic research is based on scientific books and journals; is the search for a problematization of a research project from published references, analyzing and discussing the cultural and scientific contributions. It comprises the universe of theoretical works developed in fields such as philosophy, sociology, and anthropology. However, documentary research resembles bibliographic research, but the sources that constitute it are documents and not only published books and scientific articles published, as is the case of bibliographical research.

Exploratory research consists of conducting a study to familiarize the researcher with the object of the investigation; allows you to choose the most appropriate techniques for your research, so you can determine the issues that need the most attention during the investigation. With exploratory research it is possible to discover new phenomena and formulate new ideas and hypotheses.

In this article the qualitative methodology was used, because we believe that its use is essential insofar as, according to Bogdan \& Biklen [7], the qualitative method allows to describe a more in-depth study through the presentation of the meaning, and the subjectivity of the individuals, a since the qualitative study captures the ideas of each individual on each subject.

Also resort to bibliographic research to gather the information and data that will serve as a basis for the construction of the research that we propose to develop on this topic. Also was used exploratory research with the purpose of obtaining a greater proximity to the reality of the object studied. 


\section{Historical Cost ANd FAIR VALUE}

The management of an agricultural entity implies the need to take decisions on an ongoing basis. The quality of these decisions depends to a large extent on the characteristics of the information available at the appropriate time. Up-to-date accounting records enable timely information to be made available to ensure successful decision-making.

Fair value accounting is a controversial issue, but attention usually goes to fair valuation of financial instruments [8]. First of all, it is necessary to know that the measurement is based on essential criteria (measurement bases) defined in the conceptual framework of accounting (IASB), namely:

a) the usefulness of the decision;

b) qualitative characteristics of financial information;

c) comprehensibility;

d) relevance - predictive value, feedback value, timing;

e) reliability - reliable representation, neutrality, verifiability;

f) comparability;

g) concept of assets and liabilities;

h) how to measure the equivalents of expected cash flows of assets and liabilities?

i) Cost / benefit considerations.

Traditionally, the measurement method most used by accounting is historical cost, being very popular in continental Europe; however, in recent years, alternatives to asset and liability measurement have arisen and, within these, fair value measurement. When using historical cost, the principle of prudence must be applied, which is why we cannot revalue the assets for higher values, but rather for smaller values, in which case we need to calculate the impairment. Proponents of this measurement basis argue that the historical cost is more objective, verifiable, easy to understand and represents the asset's acquisition value. However, over time, the same value may no longer represent the expectation of future economic benefits or have a shorter useful life or become obsolete.

For the IASB, fair value is the amount by which an asset can be exchanged, or a liability settled between knowledgeable and willing parties in a transaction in which there is no relationship between them. The IASB issued IFRS 13 - Fair Value Measurement in May 2011 as a common basis on measurement at fair value when its determination is required or permitted by another accounting standard.

This new standard defines the concept of fair value and has become the guiding reference in measuring at fair value. Prior to the introduction of IFRS 13 there was no guidance on the measurement of fair value and inconsistencies in determining the fair value of an asset in the accounting standards added complexity to the process of preparing the financial statements.

IFRS 13 defines fair value as the "exit price" and thus "the price that would be received in the sale of an asset or paid to transfer a liability in an orderly transaction between the participants of a market at the measurement date".

IFRS 13 in a single standard clarifies the fair value concepts that were in other standards, establishes a conceptual framework for the measurement of fair value, the inputs to be used in valuation techniques and determines the disclosure requirements in the measurement by the fair value. This standard clarifies, in particular, that: (1) For non- financial assets, "greater and better use" is the use that market participants must make in order to maximize the value of an asset; (2) Measurement at fair value assumes that the hypothetical sale of the asset - or "sale transaction" - occurs in the "main market"; this is the market with the highest volume and activity level for the asset or liability; in the absence of a main market, the transaction is presumed to take place in the "most advantageous market". This is what maximizes the amount that would be received in the sale of the asset or minimizes the amount that would be paid to transfer the liability; the norm refers that it is the responsibility of the management organs of the company to identify the relevant market.

The disclosure requirements have been broadly extended to provide users of the financial statements with detailed quantitative and qualitative information on the assumptions and procedures used in fair value measurement. The IASB intends to clarify with the new definition of fair value that it is a market-based measure, not a company-specific measure, and that this fair value should reflect current market conditions.

International Financial Reporting Standards (IFRS) 13 uses a different approach. In this standard, the three-tiered fair value hierarchy is based on the type of inputs and not on the valuation methods. The new hierarchy is thus defined:

- Level 1 inputs are "unadjusted, quoted prices of identical assets or liabilities in active markets"; therefore, if there are quotations prices in an active market (i.e., a level 1 input), the company must use these quotations without adjustments in the fair value measurement.

- Level 2 inputs are those that are not quoted prices in an active market (level 1) and are therefore directly or indirectly observable.

- Level 3 inputs are those that are not based on observable market data and are determined on the basis of assumptions of management bodies; Level 3 inputs should, however, reflect the assumptions that would be used by market participants in determining the price of an asset.

\section{IPSAS 27 - AGRICULTURE}

IPSAS 27 - Agriculture was prepared by the International Public Sector Accounting Standards Board (IPSASB), it is extracted mainly from the International Accounting Standard (IAS) 41 - Agriculture, published by the International Accounting Standards Board (IASB). Parts of IAS 41 are reproduced in the IPSASB publication of the International Federation of Accountants (IFAC), with the permission of the International Accounting Standards Committee Foundation (IASCF). The purpose of this standard is to prescribe the accounting treatment and disclosure of agricultural activity, based on the principle of accrual.

The fair value of an asset considers its present location and condition. For example, the fair value of livestock on a farm is the price of livestock on the relevant market minus transport and other costs of obtaining livestock, either for that market or for the place where it will be distributed free of charge or for a nominal cost (IPSAS $27 \S 14$ ).

According to Karakelleoğlu \& Gönen [1], to establish the basis that will be used in the measurement of biological assets and agricultural production, the concept of fair value must be 
remembered. Fair value can be described as market values, provided that experienced buyers and sellers, willing to trade, are found in a homogeneous active market.

\section{A. Recognition and Measurement}

IPSAS 27 defines that an entity shall recognize a biological asset or agricultural product when and only when:

a) the entity controls the asset as a result of past events;

b) it is probable that future economic benefits or service potential associated with the asset will flow to the entity;

c) the fair value or the cost of the asset can be reliably measured.

According to the same rule, a biological asset must be measured at initial recognition and at each reporting date at fair value less costs to sell, except in cases where that amount cannot be measured reliably. In these situations, the biological asset is measured at cost less accumulated depreciation and less accumulated impairment losses. If an entity acquires a biological asset through a transaction without consideration, it is measured at initial recognition and at each reporting date in accordance with the criteria mentioned above (IPSAS $27 \S 16-17$ ).

Agricultural products harvested from an entity's biological assets should be measured at fair value less costs to sell at harvest time. Thereafter, it applies to IPSAS 12 - Inventories or other applicable Accounting Standard, which is the cost to be taken into consideration for accounting recognition in accordance with that Standard (IPSAS 27, § 18). Given that according to the inventory rule the initial recognition must be made at cost, this standard assumes that, for the purposes of such recognition, the fair value is equated to the cost value.

The initial and subsequent recognition of biological assets should be at fair value less costs to sell (which in the vast majority of cases will correspond to the fair value regulated, given by the information contained in the Agricultural Market Information System at the date of acquisition and the date of each balance sheet, with the respective changes to be recognized in the results. For agricultural products harvested from biological assets, the standard provides for the initial measurement and after fair value at the time of harvest.

In agricultural activity, control can be evidenced, for example, by lawful possession of cattle and by hot-tagging or otherwise at the time of acquisition, birth or weaning. Future economic benefits are usually estimated by measuring significant physical attributes.

The determination of fair value for a biological asset or agricultural product can be facilitated if they are grouped according to the significant attributes, for example, by age or quality. The entity shall identify the attributes that correspond to those that are used in the market as the basis for pricing.

Some entities often make contracts to sell their biological assets or agricultural products at a future date. Contracted prices are not necessarily relevant in determining fair value because it reflects the current market in which the buyer and the seller willing to conduct business would carry out the purchase and sale transaction. Therefore, the fair value of the biological asset or agricultural product is not adjusted according to the existence of the contract. In some cases, a contract for the sale of a biological asset or agricultural product with counterparty may be an onerous contract, as defined in IPSAS 19.

If there is an active market for a biological asset or agricultural product, considering its location and current conditions, the price quoted in that market is the appropriate basis to determine its fair value. If the entity has access to different active markets, it must use the most relevant one. For example, if the entity has access to two active markets, it must use the price that prevails in the market that it intends to use. If there is no active market, an entity shall, where available, use one or more of the following alternatives to determine fair value (IPSAS 27, § 22):

a) the market price of the most recent transaction if there has been no significant change in economic circumstances between the date of the transaction and the closing date of the financial statements.

b) market prices of similar assets with adjustments to reflect differences, and

c) industry standards such as the value of an orchard expressed by the standard export packing value, bushels or hectares, and the value of livestock expressed per kilogram of meat.

A summary can be seen in the following figure:

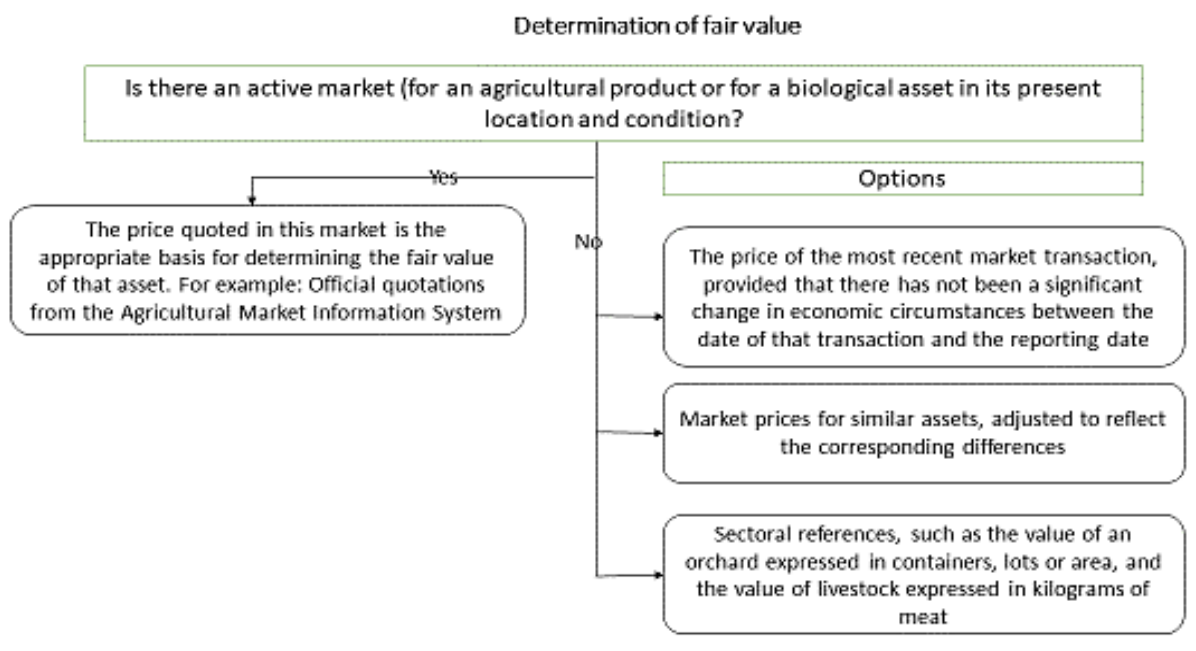

Fig. 2. Determination of fair value. Source: own elaboration. 
In some cases, the sources of the information mentioned above may suggest different conclusions about the fair value of the biological asset or agricultural product. In this situation, the reasons for such differences should be evaluated and weighted to obtain the most reliable estimate of fair value.

In some circumstances, the price or market-determined value may not be available for a biological asset under current conditions. In this case, the entity shall use the present value of the expected net cash flow of the asset, discounted at the current market rate, for the definition of the fair value. The purpose of calculating the present value of the expected net cash flow is to determine the fair value of the biological asset at the location and under the current conditions. The entity should consider this objective in determining the appropriate discount rate to be used and in estimating the expected net cash flow. In determining the present value of the expected net cash flow, an entity shall include the market participants' expectation of the net cash flow that the asset may generate in the most significant markets. The entity shall not include any cash flows for asset financing, taxes, or reinstatement of the biological asset after harvesting (for example, the cost of replanting trees in a post-harvest planting area).

In a transaction between two non-benefited parties, the buyer, and the seller willing to negotiate, according to the price, through the information of their market value, have to take into account the possibility of variations in the cash flow. In this way, the fair value should reflect the possibility of such variations. Thus, the entity should incorporate the expectation about possible variations in the cash flow, either in the elaboration of this flow, or in the discount rate, or even in the combination of the two. In determining the discount rate, the entity shall use assumptions consistent with those used in estimating the expected cash flow, to avoid omission or duplication of assumptions.

Costs may sometimes approach fair value, particularly where: (a) A small biological transformation occurs from the time of the initial cost calculation (e.g., fruit trees born from seed or seedlings planted in the period immediately prior to the closing of the financial statements); or (b) the impact of the biological asset transformation on the price is not expected to be material (for example, for the initial growth of pine planting with a production cycle of 30 years).

Biological assets are often planted on land (e.g., planted forest trees). There may not be a separate market for these assets, but there may be an active market for the combination of them, i.e., for biological assets, land without planting and land improvements. An entity may use information on combined assets to determine the fair value of biological assets. For example, the fair value of land without planting and land improvements can be deducted from the fair value of the combined assets to obtain the fair value of the biological asset.

The table below summarizes what IPSAS 27 prescribes about the determination of fair value and costs at the point of sale.
TABLE I: DETERMINATION OF FAIR VALUE AND SELLING COSTS

Determination of fair value Determination of costs at the point of sale

If there is an active market for a biological asset or agricultural product, the price quoted in that market (official market quotes provided by the Agricultural Market Information System) is the appropriate basis for determining the fair value of that asset.

If there is no active market, an entity will use one or more of the following indicators, when available, to determine the fair value:

a) The most recent transaction price on the market if there has not been a significant change in economic circumstances between the date of that transaction and that of the balance sheet.

b). Market prices of similar assets adjusted to reflect differences.

c). Industry references. If market-determined prices are not available for a biological asset in its current condition, an entity will use the fair value of the expected net cash flows of the asset, discounted at a pre-tax rate determined in the market chain.

Source: own elaboration.

\section{B. Gains and Losses}

Gains or losses from the initial recognition of a biological asset at fair value less estimated costs at the point of sale, as well as a change in fair value less estimated costs of sale (for example, the difference between cost of acquisition and fair value less estimated costs to sell) and a fair value change less estimated costs at the point of sale of a biological asset (attributable to physical changes or changes in market prices) are included in the results of the period.

Like biological assets, a gain or loss that arises on the initial recognition of an agricultural commodity measured at fair value less costs to sell (e.g., as a result of harvests) should be included in the results of the period in which it occurs.

\section{Inability to Measure Reliably the Fair Value}

There is a principle that the fair value of the biological asset can be measured reliably. However, such a premise may be rejected only if, at initial recognition of biological assets, the market-determined values or prices are not available and the alternatives for estimating them are not reliable. In such situations, such biological assets must be measured at cost, less accumulated depreciation, and any accumulated impairment losses. When the fair value of such biological asset becomes reliably measurable, the entity shall measure it at its fair value less costs to realize the sale. When the biological asset classified in non-current assets meets the criteria to be classified as an asset held for sale (or included in a group of assets held for that purpose), in accordance with the relevant national or international accounting standards that treat the non-current assets held for sale, it is assumed that the fair value can be measured reliably. 
The previous presumption can only be rejected on initial recognition. An entity that has previously measured the biological asset at its fair value less costs to sell, will continue to measure it until it is disposed of.

The entity shall measure the agricultural product at the time of harvest at its fair value, less the selling expense. IPSAS 27 reflects the theory that the fair value of the agricultural product at the time of harvesting can always be measured reliably.

In determining cost, depreciation and impairment, an entity shall consider IPSAS 12 - Inventories, IPSAS 17 - Property, Plant and Equipment, IPSAS 21 - Impairment of Non-Cash Generating Assets and IPSAS 26 - Impairment of Cash Generating Assets.

\section{Disclosures}

IPSAS 1 - Presentation of Financial Statements, reiterates that financial statements must be presented at least annually in order to provide information on the financial position, performance and changes in the financial position of an entity that is useful to a wide range of users in economic decisionmaking.

Such disclosures should be included in the notes to the financial statements and may consist of explanatory text or supplementary tables to better understand the balance sheet and the income statement.

The distinction between the concepts of consumable biological assets and production assets and, as well as the classification as mature or immature are relevant to be able to analyze in the financial statements, with reliability and quality:

a) the perspective of decision making in view of the nature and maturity of biological assets.

b) the future impact of these biological assets on results and financial position.

The distinction between consumable biological assets and production assets and their subsequent classification between mature and immature will provide stakeholders with financial information from the asset pools that will contribute to future economic benefit inflows, from a shorter-term perspective and from a medium and long term.

The adoption of the principle of fair value in biological assets and agricultural products at the time of harvesting is justified by their nature and specific characteristics. But for it to produce the desired effects it is necessary that it is reliably measured (which is not always the case). Otherwise, it leads to subjectivity and therefore to the manipulation of records, making impossible a picture of economic reality.

The entity shall disclose the gain or loss that occurred during the current period in relation to the initial recognition value of the biological asset and the agricultural product and also the changes in fair value less costs to sell the biological assets.

Consumable biological assets are those that are kept until the moment of the harvest as agricultural production or kept for sale or distribution free of charge or at a negligible value, as a biological asset.

Examples of consumable biological assets are animals and plants intended for single use, such as livestock kept for meat production, herds kept for sale, fish production, corn and wheat crops, and trees for production of sawn timber.
Biological assets for breeding and/or production are those used repeatedly or continuously for more than one year in an agricultural activity. Biological assets for breeding and/or production are not agricultural production, they are selfrenewing. Examples of types of animals that are biologically active for breeding and/or production include fish and poultry for breeding, dairy herds, and sheep or other animals used for wool production. Examples of types of plants that are biological assets for reproduction / and or production include vines, shrubs and fruit trees, trees from which products derived from sap, resin, bark, and leaves are extracted and trees from which the firewood is extracted, but with maintenance of the tree.

The entity is also encouraged to highlight the distinction between mature (consumable) and immature biological assets, as appropriate. These distinctions provide information that may be helpful in forecasting future cash flow and service potential. The entity shall highlight the criteria used to make such distinctions.

If the entity has not evidenced the elements that follow in any other document published together with the financial statements, it must describe (evidence) the following elements:

a) the nature of the activities involving each group of biological assets; and

b) non-financial measurements or estimates of physical quantities:

c) each group of biological assets of the entity at the end of the period;

d) agricultural production during the period.

The entity shall demonstrate the significant method and assumptions applied in determining the fair value of each group of agricultural products at the time of harvest and each group of biological assets.

The entity shall record the fair value, less the selling expense of the crop harvested during the period determined at the time of harvest.

The entity must also show:

a) the existence and total book value of biological assets whose legal ownership is restricted, and the total book value of biological assets given as a guarantee of liabilities.

b) the nature and extent of restrictions on the entity's ability to use or sell biological assets.

c) the number of commitments related to the development or acquisition of biological assets;

d) strategies for managing financial risks related to agricultural activity.

The entity shall present the reconciliation of changes in the book value of biological assets between the beginning and end of the current period. The reconciliation includes:

a) gain or loss arising from the change in fair value less costs to sell, evidenced separately for biological assets for breeding and / or production and biological consumable assets.

b) increases due to purchases.

c) increases due to assets acquired through non-exchange transactions.

d) reductions attributable to sales and biological assets classified as held for sale / disposable assets in accordance with relevant international or national accounting standards dealing with non-current assets held for sale and discontinued 
operations.

e) reductions due to free distribution or irrelevant value.

f) crop reductions.

g) resulting increase in business combination.

h) net exchange differences arising from the conversion of the financial statements to another presentation currency and, also, from the conversion of operations in foreign currency to the presentation currency of the entity's statements;

i) other changes.

The fair value less the expense of selling a biological asset may change due to physical changes and changes in prices in the market. Separate disclosure of physical changes in price changes is useful for assessing the performance of the current period and for future projections, particularly when there is a production cycle of more than one year. In such cases, the entity is encouraged to disclose, by group or otherwise, the total amount of the change at fair value less the selling expense, included in the result (surplus and deficit), the amount referring to the physical changes and the value price changes in the market, separately. Generally, this information is not as useful when the production cycle is less than one year.

Biological transformation results in various types of physical changes - growth, degeneration, production, and procreation, each of which can be observed and measured. Each of these physical changes is directly related to future economic benefits or service potential. The change in the fair value of biological assets due to the harvest is also a physical change.

Agricultural activity is often exposed to climatic hazards, diseases, and other natural hazards. If an event occurs and gives rise to a material item of income or expense, the nature and value of that item shall be evidenced in accordance with IPSAS 1 - Presentation of the Financial Statements. Examples of such events include viruses, floods, drought, frost, and insect pests. Additional disclosure of the biological asset is required if the fair value cannot be measured reliably.

If the entity assesses biological assets at cost, less any depreciation and impairment, at the end of the period it must provide the following information regarding such biological assets:

a) a description of the biological assets.

b) an explanation of why fair value cannot be measured reliably.

c) if possible, an estimate within which there is a high probability of finding the fair value.

d) the depreciation method used.

e) the useful life or the depreciation rate used;

f) gross book value and accumulated depreciation (plus accumulated impairment loss) at the beginning and end of the period.

If during the current period the entity evaluates the biological assets at its cost less accumulated depreciation and impairment, it must disclose any recognized gain or loss on the disposal of such biological assets. The reconciliation shall disclose the amounts related to such biological assets, separately. In addition, the reconciliation shall contain the following amounts, included in the result (surplus or deficit) and arising from those biological assets:

(a) losses due to recoverable amount.

(b) reversal of impairment losses; and (c) depreciation.

If the fair value of the biological assets previously measured at cost less any accumulated depreciation and impairment becomes reliably measurable during the current period, the entity shall disclose the following information on these biological assets:

(a) a description of the biological assets.

(b) an explanation of why fair value has become reliably measurable; and

(c) the effect of the change.

\section{AdVAntages AND DisAdVANTAGES OF FAIR VALUE}

Taking into account Marra [9], there are advantages arising from the use of this measurement basis, namely, greater relevance, reliability, comparability and comprehensibility in the measurement of future economic benefits of biological assets traded in active markets; the measurement on the date of the financial statements of long production cycles, with volatility in production and in the market, is a better measure of performance evaluation; the effect of biological transformation is best reflected in changes in fair value.

However, it also has some disadvantages, such as: fair value is based on subjective assumptions; the market price is volatile and costly to obtain; the lack of active markets in some countries, especially during the period of growth; the recognition of unrealized gains and losses; the lack of a relationship between market prices and the sale price; they may not be biological assets held for sale (for example for production).

\section{AGRICULTURAL MARKET INFORMATION SYSTEM} (SIMA)

In Portugal, SIMA was created by Decree-Law no. 91/85, of April 1, under the Office of Planning and Policies of the Ministry of Agriculture, Rural Development and Fisheries, and its main objective is the follow-up for the purpose of collecting the prices / prices of the products and the qualitative or quantitative information (quantities, stocks, etc.) necessary to characterize the conditions for disposal of the products. SIMA enables the Planning and Policy Office to obtain harmonized information throughout the territory, which it uses to support the positions taken and decisions taken in the context of agricultural policy.

This system operates in two markets: those of production and suppliers and wholesalers and tries to follow the various sectors of agricultural activity.

SIMA collects data to inform policymakers, who have the task of monitoring market policies (national or Community) and inform the market itself and its agents by providing a public service to help market transparency. This system offers official quotations that serve as a benchmark for determining the fair value of this type of asset but are insufficient to the extent that they do not cover all biological assets and agricultural products. 


\section{COMPARISON WITH IAS 41}

IPSAS 27 was mainly inspired by IAS 41 - Agriculture. The main differences between IPSAS 27 and IAS 41 are as follows:

- The definition of "agricultural activity" includes transactions for distribution of biological assets free of charge or for irrelevant value. IAS 41 does not deal with such transactions.

- Clarifies that biological assets held for the supply or provision of services are not addressed in this Standard. IAS 41 does not include such clarifications.

- IAS 41 includes requirements for government subsidies related to biological assets measured at fair value less costs to sell. IPSAS 27 does not include requirements and guidance for government subsidies because the matter is already addressed in IPSAS 23 - Revenue from Non-Exchange Transactions (Taxes and Transfers), which provides requirements and guidance related to government subsidies on non-exchange transactions.

- IPSAS 27 contains requirements for measurement at the initial recognition, and at each date of the financial statements, of biological assets acquired through nonexchange transactions.

- This Standard contains an additional disclosure requirement for biological assets for which the entity's ability to use or sell is subject to restrictions.

- IPSAS 27 contains a requirement to distinguish between consumable biological assets and biological assets for breeding / production and to distinguish between those biological assets held for sale and those biological assets held for free distribution or irrelevant value. Such disclosures take the form of a quantitative description that can be accompanied by a narrative description. IAS 41 encourages, but does not require, entities to provide a quantitative description of each group of biological assets, distinguishing between consumables and for production, or between mature and immature biological assets, as appropriate.

- IPSAS 27 uses, in certain circumstances, different terminologies from IAS 41. The most significant examples are the use of terms of future economic benefits or potential for services, surplus or deficit, and statement of financial performance (income statement for the year). The equivalent terms in IAS41 are future economic benefits, profit or loss, income statement.

\section{CONClusions}

Although the role of the agricultural sector is irreplaceable in the economy, due to the rapid change that the globalization process has brought about, agricultural transactions need to be harmonized with the current expansion of international trade. The adoption of the IASB's rules by the European Union makes it possible to avoid important differences that have existed before. Portugal adopted these standards and IPSAS when it approved the SNC-AP, in use from 2018 by most of the public entities.

The adoption of IPSAS increases transparency and accountability in the public sector and improves the credibility of financial statements. The preparation of financial statements in accordance with IPSAS is essential, as it results in the comparability, relevance, and reliability of these statements, resulting in quality reports.

For years, biological assets were measured only at historical cost, representing costs measured over time. With the adoption of international accounting standards, when there is an active market, fair value can be used with confidence in agriculture, since it is closer to reality.

IASB regulation in the field of agriculture allows users of financial information to obtain information more consistent with real market conditions. Such regulations give relevance to specific facts of agriculture, including transformation, growth, decay, and reproduction. In this way, it facilitates the provision of reliable and truthful information to decisions related to agriculture.

\section{REFERENCES}

[1] Karakelleoğlu, M. I. \& Gönen, S. (2017). An Insight on Accounting for Agricultural Transactions: Recent Perception of IAS 41 With Applications. Ecoforum, Volume 6, Issue 1(10), 2017.

[2] Orbán, I., Dékan, T. \& Kiss, A. (2015). Measurement of agricultural activities according to the International Financial Reporting Standards. Procedia Economics and Finance 32 (2015) 777-783.

[3] Marques, M. C. (2018). Public Accounting and IPSAS in Portugal: The Accounting Standardization System for Public Administrations. Journal of Modern Accounting and Auditing, April 2018, Vol. 14, No. 4, 153-164 - doi: 10.17265/1548-6583/2018.04.001

[4] Quivy, Raymond; Champenhoudt, Luc Van, Manual de Investigação em Ciências Sociais, Lisboa, Edições Gradiva, 2005.

[5] Garcia, L.; Quek, F. (1997). Qualitative research in information systems: time to be subjective?, In: Lee, A. S.; Liebenau, J.; Degross, J. I. (ed.) Information systems and qualitative research, London, UK: Chapman \& Hall, pp. 444-465

[6] Godoy, A. S. (1995). Pesquisa qualitativa - tipos fundamentais. Revista de Administração de Empresas, 35(3), 20-29.

[7] Bogdan, R., Biklen, S., (1994). Investigação Qualitativa em Educação - uma introdução à teoria e aos métodos. Porto: Porto Editora.

[8] Adwana, S., Alaa Alhaj-Ismail, A. \& Girardonec, C. (2020). Fair value accounting and value relevance of equity book value and net income for European financial firms during the crisis. Journal of International Accounting, Auditing and Taxation, Volume 39, June 2020, 100320, https://doi.org/10.1016/j.intaccaudtax.2020.100320.

[9] Marra, A. (2018). The Pros and Cons of Fair Value Accounting in a Globalized Economy: A Never Ending Debate. Journal of Accounting, Auditing and Finance 31(4):582-591 - October 2016 with 282 Reads. DOI: $10.1177 / 0148558 X 16667316$.

[10] Comissão de Normalização Contabilística (2015). Norma Contabilística e de Relato Financeiro 17 - Agricultura.

[11] Comissão de Normalização Contabilística (2015). Norma de Contabilidade Pública 11 - Agricultura.

[12] Comissão de Normalização Contabilística (2015). Sistema de Normalização Contabilística para as Administrações Públicas (SNC.AP).

[13] Epstein, B.J., Mirza, A.A. (2003). IAS 2003: Interpretation and Application of International Accounting Standards. Jon Wiley\&Sons Inc.

[14] Herborn, K., Herborn, J. (2006). International Accounting Standard (IAS) 41: What Are the Implications for Reporting Forest Assets. Small-scale Forest Economics, Management and Policy, 5 (2).

[15] IAS 41 Agriculture - Recognition and Measurement of Biological Assets and Agricultural Produce in accordance with IAS 41. Retrieved from http://www.ifrs.org/Current-Projects/Project-Archive/IAS-41Agriculture-Recognition-and-Measurement-of-Biological-AssetsandAgricultural-Produce-in-ac/Pages/IAS-41-Agriculture-Recognition-and-Measurement-of-Biological-Assets-andAgriculturalProduce-in-ac.aspx. accessed June 2018.

[16] IAS 41 Agriculture from http://www.iasplus.com/en/standards/ias/ias41.

[17] IPSASB (2011). IPSAS 27 - Agriculture.

[18] Orbán Mrs. Tamás Dékán, I., (2013). Reporting companies' performance - in respect of the International Financial Reporting Standards. Applied Studies in Agribusiness and Commerce APSTRACT. Retrieved from https://ageconsearch.umn.edu/record/187516/files/15_Orban.pdf. 
European Journal of Business and Management Research www.ejbmr.org

Accessed December 2018.

[19] Decreto-Lei ${ }^{\circ}$ 192/2015 - aprova o Sistema de Normalização contabilística para as Administrações Públicas (SNC-AP). Available in http://www.cnc.min-

financas.pt/pdf/SNC_AP/DL_192_2015_11Set_SNCAP.pdf.

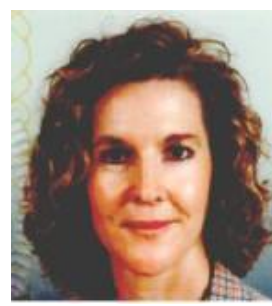

Maria da Conceição da Costa Marques is $\mathrm{PhD}$ in Management, Specialization in Accounting, Master in Accounting and Corporate Finance and Bachelor in Management Control. Also is chairman of the Technical-Scientific Council of the Higher Institute of Accounting and Administration of Coimbra, President of the Scientific Board of the Centre for Studies in the History of Accounting of APOTEC, Coordinator Professor of the Higher Institute of Accounting and Administration of Coimbra - Teaches courses in Bachelor and Master and invited as Associate Professor in Faculty of Law of University of Coimbra (accumulation). 